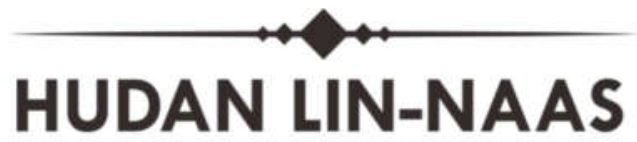

Jurnal Ilmu Sosial dan Humaniora

Volume: 2, no 1, Januari-Juni 2021

ISSN : 2775-1198 (print); 2775-2755 (online)

http://ejournal.idia.ac.id/index.php/hudanlinnaas/indeX

\title{
PERTUNANGAN \\ DALAM PERSPEKTIF ORANG MADURA
}

\author{
Moh. Maqbul Mawardi dan Imrotul Konita \\ Institut Dirosat Islamiyah Al-Amien Prenduan Sumenep \\ maqbul.mohammad.m@gmail.com, imrotul.k@gmail.com
}

\begin{abstract}
Abstrak
Artikel ini membahas tentang pertunangan di Madura. Bagi masyarakat Madura, pertunangan tidak hanya dilihat dari sisi syariat Islam, namun juga budaya. Hal ini disebabkan budaya merupakan suatu hal yang dilakukan oleh masyarakat dan seakan-akan menjadi hukum tersendiri bagi lingkungannya. Terutama bagi warga Dusun Batu Jaran Desa Pragaan Daya Kecamatan Pragaan, Kabupaten Sumenep.

Penelitian ini menggunakan pendekatan kualitatif, dengan teknik pengumpulan data berupa wawancara dan dokumentasi. Teknik pemeriksaan keabsahan data dilakukan dengan perpangjangan keikutsertaan, ketekunan pengamatan dan triangulasi.

Dari hasil penelitian dapat disimpulkan bahwa pertunangan yang ada di Dusun Batu Jaran Desa Pragaan Daya Kecamatan Pragaan adalah budaya pintaan, budaya ngoniin bakal dan budaya ain-main. Hampir seluruh orang tua yang sudah mempunyai anak bertunangan beranggapan bahwa apa yang terjadi dalam tradisi, dan budaya dalam pertunangan di daerah ini merupakan hal yang sudah biasa. Beberapa orang tua mengemukan bahwa calon menantu sudah seperti anak sendiri.
\end{abstract}

\section{Kata Kunci.: Pertunangan, Madura}

\section{Abstract}

This article discusses engagement in Madura. For the Madurese, engagement is not only seen from the perspective of Islamic law, but also culture. This is because culture is something that people do and seems to be a separate law for their environment. Especially for the residents of Batu Jaran, Pragaan Daya, Pragaan, Sumenep. 
This study uses a qualitative approach, with data collection techniques in the form of interviews and documentation. The technique of checking the validity of the data is done by extending the participation, persistence of observation and triangulation.

From the results of the study, it can be concluded that the engagement in Batu Jaran, Pragaan Daya, Pragaan, is a request culture, a dating culture, and a visiting culture. Almost all parents who already have engaged children think that what happens in tradition, and culture in engagement in this area is a common thing. Some parents find that their future daughter-in-law is like their own child.

\section{Keywords : Engagement, Madura}

\section{Pendahuluan}

Kebudayaan tidak bisa dipisahkan dari masyarakat yang mana budaya merupakan sesuatu yang dilakukan masyarakat secara berlanjut Nasibahingga budaya seakan-akan menjadi hukum yang tertulis bagi masyarakat maka dari itu masyarakat mengkaitkan budaya dengan kehidupannya.

Pertunangan dalam bahasa arab disebut khitbah yang artinya menyampaikan permintaan. Maksud dengan menyampaikan permintaan di sini adalah menyampaikan keinginannya kepada walinya baik secara langsung atau mengutus orang lain yang dipercaya dengan tujuan untuk menikah sekaligus mengetahui tanggapan dari pihak yang dipinang, baik berupa penerimaan atau penolakan. ${ }^{1}$

Islam mensyariatkan pertunangan sebelum dilaksanakan ikatan perkwaninan agar mengenal pasangannya sehingga memantapkan hati untuk membangun rumah tangga. ${ }^{2}$ Pertunangan dalam islam disyariatkan karena dengan adanya pertunangan kedua pihak bisa mengenalnya. Sedangakan tujuan dari pertunangan adalah untuk lebih menguatkan ikatan perkawinan karena dengan pertunangan pihak laki-laki dan pihak perempuan dapat saling mengenal. ${ }^{3}$ Pada masa tunangan itulah mereka akan mengetahui tabiatnya masing-masing setelah mengenalnya maka akan lebih mudah membangun rumah tangga yang baik.

Budaya pertunangan yang disyariatkan dalam Islam yang pertama melihat ketika melakukan pertunangan, karena dengan melihat pihak laki-laki bisa mengetahui kepada calon wanita dan akan menguatakkan ikatan perkawinan. ${ }^{4}$ Kedua Ta'aruf adalah proses perkenalan

\footnotetext{
${ }^{1}$ Amir Syarifuddin, Hukum Perkawinan Islam Di Indonesia (Jakarta: Prenada Media, 2006),49.

2 Sayyid Sabiq, Fiqih Sunnah Jilid 3 (Mataram: Tinta Abadi Gemilang, 2013), 221.

3 Amir Syarifuddin, Hukum Perkawinan Islam Di Indonesia, hal 50.

${ }^{4}$ Abdul Hayyie Al kattani, dkk, Fiqih islam, (Depok: Gema Insani, 2016), 21
} 
dengan tujuan untuk menikah, dalam proses ta'aruf harus didampingin oleh mahrom pihak perempuan. ${ }^{5}$

Islam tidak membolehkan melakukan sesuatu kepada tunangannya kecuali melihat ketika proses tunangan. Kepada perbuatan-perbuatan lainnya hukumnya tetap haram. ${ }^{6}$ karena ketika tunangan melakukan seperti berduaan maka akan dikhawatirkan terjerumus melakukan sesauatu yang dilarang oleh agama.

Dusun Batu Jaran Pragaan Daya salah satu daerah yang terletak di daerah Sumenep, desa ini memiliki sumber daya alam yang tinggi seperti pohon kelapa, siwalan. Moyaritas pemuda di desa tersebut berpendidikan berbasis islami dari sejak kecil Nasibahingga mereka mendapatkan kehidupan yang lebih baik.

Akan tetapi di zaman modern yang seperti ini tidak cukup untuk menggeser budaya yang sudah bertahun-tahun berjalan di Desa Batu Jaran Pragaan Daya Sumenep walaupun pemudanya sudah banyak yang berpendidikan berbasis islami di desa tersebut. Pelaksanaan pertunangan yang dilakukan oleh masyarakat Dusun Batu Jaran Desa Pragaan daya Kecamatan Pragaan Kabupaten Sumenep sama halnya dengan memberikan kebebasan kepada pihak laki-laki maupun perempuan.

Kajian tentang pertunangan salah satunya dilakukan oleh Theadora Rahmawati menyebutkan bahwa pertunangan merupakan salah satu solusi efektif dalam menjaga pergaulan negatif, akan tetapi ada juga yang menyebutkan bahwa pertunangan dan perkawinan dijadikan sebagai ladang bisnis. Hal tersebut dilatarbelakangi oleh nilai-nilai agama, menjaga kehormatan, ekonomi dan budaya. ${ }^{7}$

\section{Metode Penelitian}

Penelitian ini menggunakan pendekatan kualitatif lapangan, studi kasus. ${ }^{8}$ Dengan pengumpulan data melalui: wawancara, ${ }^{9}$ observasi, ${ }^{10}$ dan dokumentasi. ${ }^{11}$ Adapun tahapan yang ditempuh ada tiga tahapan, yaitu sebagai berikut: pertama tahap pra lapangan; yaitu terdiri dari menyusun rancangan penelitian, memilih lapangan penelitian, mengurus penelitian, menjajaki

\footnotetext{
5 Luky Rouf, Yuk Move one Dari Cinta Turun Ke Hati, (Bogor: Al-Azhar Fresh Zone, 2014), 96

6 Munir Anshari, Kado perkawinan (Sumenep: Iman Bela, 2000), 57.

7 THEADORA RAHMAWATI, "TINJAUAN HUKUM ISLAM TERHADAP ADAT PERTUNANGAN DAN PERKAWINAN PADA MASYARAKAT DESA LONGOS, KECAMATAN GAPURA, KABUPATEN SUMENEP” (skripsi, UIN SUNAN KALIJAGA YOGYAKARTA, 2017), http://digilib.uin-suka.ac.id/id/eprint/25154/. 8 Lexy J. Moleong, Metodologi Penelitian Kualitatif (Bandung: PT. Remaja Rosdakarya, 2011), 155.

9 Mohammad Nazir, Metode Penelitian (Jakarta: Galia Indonesia, 2006), 193-194.

10 Sumadi Suryabrata, Metodelogi Penelitian Kualitatif (Jakarta: Rajawali Perss, 1991), 94.

11 Cholid Narbuko dan Abu Ahmadi, Metodologi Penelitian (Jakarta: Bumi Aksara, 2001), 70.
} 
dan menilai keadaan lapangan, memiliki dan memanfaatkan informan, menyiapkan perlengkapan penelitian, mengantisipasi persoalan etika penelitian. Tahap kedua yaitu tahap Pekerjaan Lapangan; yang terdiri dari memahami penelitian dan persiapan diri, memasuki lapangan, berperan serta sambil mengumpulkan data.

Sedangkan yang terakhir yaitu tahap Analisis Data; meliputi kegiatan organisasi dan kategorisasi data, menemukan tema dan merumuskan hipotesis, serta menganalisis atau mendeskripsikan data berdasarkan hipotesis.

\section{Hasil dan Pembahasan}

\section{Budaya Pertunangan di Madura}

Pertunangan merupakan upaya untuk merencanakan pernikahan bagi kedua pihak, hanya sebatas terikat janji saja, yang mana keduanya belum mempunyai hak dan kewajiban. Karena pertunangan ada dua kemungkinan, mungkin akan jadi dan mungkin akan batal.

Pertunangan menurut warga dusun Batu Jaran adalah ketika kedua pihak saling menyukai dan pihak laki-laki menyampaikan permintaan kepada pihak perempuan yang mana pihak laki-laki membawa baju dan peralatan make up. Bagi masayarakat Batu Jaran pertunngan dilaksanakan ketika kedua anak saling suka, maka orang tua yang cowok memberika tanda agar tidak dilamar orang lain. ${ }^{12}$

Hal ini berkesesuaian dengan makna dari pertunangan itu sendiri, yakni kata pertunangan خطب يخطب خطب خب yang berasal dari dalam bahasa Arab disebut khitbah yang berasal dari kata yang artinya menyampaikan. ${ }^{13}$ Maksud dari menyampaikan di sini adalah menyampaikan keinginannya untuk menikah kepada walinya baik secara langsung maupun melalui orang lain. Ulama' fiqih mendifinisikan pertunangan adalah mengungkapakan keinginan untuk menikah dengan seorang perempuan tertentu dan memberitahunya keperempuan tersebut dan walinya. ${ }^{14}$

Menurut Imam Syafie hukum pertunangan mustahab (dianjurkan) karena Rasulullah pernah melakukan pertunangan terhadap Aisyah. ${ }^{15}$ Menurut pendapat Dawud Zhiri hukum pertunangan wajib, sedangkan menurut mayoritas ulama' pertunangan tidak menjadi sahnya

\footnotetext{
12 Wawancara dengan Nasibah

${ }^{13}$ Amir Syarifuddin, Hukum perkawinan islam di Indonesia, 49.

14 Ali Mansur, Hukum dan etika pernikahan dalam islam (malang: UB Press, 2017$), 2$.

${ }^{15}$ M. Dahlan, Fiqih munakahat (Yogyakarta: Budi Utama, 2015), 13.
} 
pernikahan. ${ }^{16}$ Islam mensyariatkan pertunangan sebelum melaksanakan akad nikah agar masing masing pihak mengetahui pasangannnya yang akan menjadi pendampingnya. ${ }^{17}$ Penjelasan pertunangan sebelum akad nikah adalah dalam rangka menuju jenjang pernikahan, pertunangan tersebut yang disyariatkan oleh Islam. Maka dari itu ketika seseorang belum mempunyai keinginan untuk menikah maka lebih baik tidak menerima pertunangan dan tidak bertunangan.

Dalam prosesi pertunangan, masyarakat Dusun Batu Jaran memiliki tradisi sebagai berikut: pintaan, Maksud pintaan disini adalah ketika kedua pihak saling suka maka orang tua atau wali pihak laki-laki meminta kepada wali pihak prempuan untuk dijadikan calon istri. Setelah pihak prempuan menerima pihak laki-laki, pihak laki-laki membawa baju, bedak, cincin sebagai tanda klo sudah menjadi resmi bertunangan. ${ }^{18} \mathrm{Ngonii}$ Bakal: Salah satu Budaya pertunangan yang ada di dusun Batu Jaran Desa Pragaan Daya Kecamatan Pragaan Kabupaten Sumenep adalah budaya ngoniih bekal mkasud dari budaya tersebut, ketika malem lebaran, pihak laki-laki menjemput tunangannya. Setelah itu pihak prempuan ikut dan menginap dirumah calon martunya setelah sholat idul fitri atau adha pulang kerumah pihak prempuan dan saling bersilaturrahmi kerumah famili-famili kedua pihak. ${ }^{19}$ Ain main: Budaya ain-main disini adalah pihak laki-laki menjemput pihak prempuan untuk mengajak maen atau memperkenalkan pihak prempuan ke saudara-saudara atau ke keluarga-keluarga yang lain dari pihak laki-laki. ${ }^{20}$

Apa yang dilakukan oleh masyarakat Dusun Batu Jaran Desa Pragaan Daya Kecamatan Pragaan Kabupaten Sumenep bisa dikategorikan dalam upaya mencapai tujuan dari pertunangan. Dimanan menurut Sayid Sabiq tujuan pertunangan adalah agar antara pihak laki dan pihak perempuan saling mengenal sedangkan menurut Syarifuddin untuk lebih menguatkan ikatan pernikahan setelah masa tunangan, karena dengan pertunangan tersebut kedua belah pihak saling mengenalnya. ${ }^{21}$

Dengan adanya pertunangan orang lain mengatahui bahwa perempuan yang dilamar merupakan calon istri bagi laki-laki yang melamarnya dan sebaliknya, atau untuk saling

\footnotetext{
16 lbid 3

17 Husein Muhammad yusuf, Memilih Jodoh \& Peminang dalam Islam, (Depok: Gema Insani, 2007) 21

18 Wawancara dengan Bapak Santawi, Ibu Nasibah, Ibu Badriah dan Bapak Lutfi

19 Wawancara dengan Bapak Santawi, Ibu Nasibah, Ibu Badriah, Bapak Lutfi, Lestia citra Dewi, Raudatul Jannah, dan Subriah

20 Wawancara dengan Bapak Santawi, Ibu Nasibah, Ibu Badriah, Bapak Lutfi, Lestia citra Dewi, Raudatul Jannah, dan Subriah

${ }^{21}$ Mardani, Hukum Keluarga Islam di Indonesia (Jakarta: Kencana, 2016), 17-18.
} 
mengenal antara kedua pihak dan untuk saling mengetahui Akhlaq, tabiat, kelebihan dan kekurangan masing-masing pihak.

Jadi dengan adanya pertunangan tersebut kedua belah pihak bisa mengenal lebih dalam sifat, krakter, tabiat, kekurangan dan kelebihan masing-masing pihak. Akan tetapi mengenal masing-masing pihak hanya sebatas yang diperbolehkan syariat Islam saja.

Budaya pertunangan yang terjadi di masyarakat Dusun Batu Jaran Desa Pragaan Daya Kecamatan Pragaan Kabupaten Sumenep ialah goncengan bersama tunangannya, menginap di rumah calon mertua ketika di rumah calon martua ada acara, dan melayani tunangannya ketika tunangannya mau makan sebagai rasa hormat kepada tunangannya. Ketika pihak perempuan tidak mau melakukan hal tersebut maka akan jadi salah satu tanda problematika pertunangan. ${ }^{22}$

\section{Persepsi Masyarakat Madura tentang Pertunangan}

Ulama' fiqih mendifinisikan pertunangan adalah mengungkapakan keinginan untuk menikah dengan seorang perempuan tertentu dan memberitahunya kepada perempuan tersebut dan walinya. ${ }^{23}$

Pertunangan merupakan upaya yang dilakukan untuk mendahului rangka perkawinan dan pertunangan bukan memberikan kebebasan kepada pihak laki-laki maupun perempuan karena mereka masih asing. ${ }^{24}$

Berdasar hal tersebutlah masyarakat Dusun Batu Jaran Desa Pragaan daya Kecamatan Pragaan Kabupaten Sumenep mengizinkan ketika putri atau putranya keluar bersama dengan tunangan dengan alasan karena sudah resmi menjadi tunangan bahkan mengannggap hal biasa, asalkan mereka izin terlebih dahulu. ${ }^{25}$ Selain itu orang tua akan merasa senang ketika anaknya pergi bersama tunangannya dengan alasan karena ketika keluar dengan tunangannya tidak akan timbul fitnah atau omongan yang tidak enak dari tetangga bahkan orang tua juga merasa senang karena keluar bersama orang yang dicintai oleh anaknya.

Orang tua merupakan orang yang bertanggung jawab dan pendidik pertama terhadap anak-anaknya. Sedangkan orang tua secara bahasa memiliki beberapa makna yaitu orang yang sudah tua, ibu bapak dan orang yang sudah di anggap tua, dalam bahasa Arab orang tua

22 Wawancara dengan Noer Zakiya

${ }^{23}$ Ali Mansur, Hukum dan etika pernikahan dalam islam, 2.

${ }^{24}$ Husein Muhammad Yusuf, Jodoh Memilih Jodoh\&peminang Dalam Islam, (Depok: gema insan, 2014), 114.

25 Wawancara dengan Santawi, Nasibah 
disebut الولد yang artinya ibu dan bapak. ${ }^{26}$ Sedangkan orang tua secara istilah adalah laki-laki dan perempuan yang sudah terikat pernikahan yang sudah siap bertanggung jawab sebagai ibu dan bapak terhadap anak-anaknya. ${ }^{27}$

Anak merupakan anugerah Allah yang dititipkan kepada orang tua yang mana orang tua harus bertanggung jawab terhadap titipan Allah. ${ }^{28}$ Sebagai wujud rasa tanggung jawab terhadap anak dengan melingdungi dan menjaganya dan memperhatikan apa saja yang berhubungan dengan anak, sampai masalah jodohpun. Kecintaan tersebut sudah menjadi fitrah orang tua terhadap anak.

Maka dari itu orang tua yang sudah mempunyai anak yang bertunangan mengawasi dan memberikan arahan kepada anak-anaknya sebagai rasa tanggung jawab orang tua terhadap anak-anaknya yang sudah bertunangan.

\section{Penutup}

Masyarakat Dusun Batu Jaran Desa Pragaan daya Kecamatan Pragaan Kabupaten Sumenep yang sudah mempunyai anak bertunangan beranggapan bahwa budaya pertunangan yang dipaparkan di atas merupakan hal yang sudah biasa. Beberapa orang tua mengemukan bahwa calon menantu sudah seperti anak sendiri. Namun meskipun begitu perlu kiranya prosesi pertunangan dan budaya atau tradisi yang melekat dengan pertunangan bisa ditinjau dari perspektif nilai-nilai dan ajaran agama Islam. Berdasar inilah, para pemuka agama harus hadir dan memberikan pengertian kepada masyarakat.

\section{Daftar Pustaka}

Abu Syauqina dkk. Fiqih Sunnah Jilid 3. Mataram: Tinta Abadi Gemilang, 2013.

Abdul Hayyie Al kattani, dkk, Fiqih Islam, Depok: Gema Insani, 2016

Ali Mansur. Hukum dan etika pernikahan dalam islam. malang: UB Press, 2017.

Amir Syarifuddin. Hukum perkawinan islam di Indonesia. jakarta: prenada media, 2006.

Ayuha. konsep pendidikan anak sholeh dalam islam. Yogyakarta: budi Utama, 2107.

Husein Muhammad yusuf (last). Jodoh Memilih Jodoh\&Peminang dalam Islam, Depok: gema Insan, 2014.

Luky Rouf, Yuk Move one Dari Cinta Turun Ke Hati, Bogor: Al-Azhar Fresh Zone, 2014

\footnotetext{
${ }^{26}$ Ayuha, konsep pendidikan anak sholeh dalam islam (Yogyakarta: budi Utama, 2107), 75-76.

27 Ibid., 76.

28 Syihabudin, Mendidik anak laki-laki (depok: Gema Insani, 2007), 12.
} 
M. Dahlan. Fiqih munakahat. Yogyakarta: Budi Utama, 2015.

Mardani. Hukum Keluarga Islam di Indonesia. Jakarta: kencana, 2016.

Moleong, Lexy J. Metodologi Penelitian Kualitatif. Bandung: PT. Remaja Rosdakarya, 2011.

Munir Anshari,. Kado perkawinan. Sumenep: Iman Bela, 2000.

Narbuko, Cholid, dan Abu Ahmadi. Metodologi Penelitian. Jakarta: Bumi Aksara, 2001.

Nazir, Mohammad. Metode Penelitian. Jakarta: Galia Indonesia, 2006.

Suryabrata, Sumadi. Metodelogi Penelitian Kualitatif. Jakarta: Rajawali Perss, 1991.

Syihabudin. Mendidik Anak laki-laki. Depok: Gema Insani, 2007.

Theadora rahmawati, nim 13350071. "tinjauan hukum islam terhadap adat pertunangan dan perkawinan pada masyarakat desa longos, kecamatan gapura, kabupaten sumenep." Skripsi, uin sunan kalijaga yogyakarta, 2017. http://digilib.uin-suka.ac.id/id/eprint/25154/. 